\title{
SIFILIS SECUNDÁRIA - CORRELAÇÃO CLÍNICO PATOLÓGICA
}

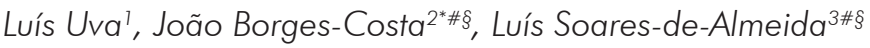 \\ 'Interno de Dermatologia e Venereologia/Resident, Dermatology and Venereology, Serviço de Dermatologia/ \\ Dermatology Department, Hospital de Santa Maria - Centro Hospitalar Lisboa Norte (CHLN) \\ ${ }^{2}$ Assistente HospitalarGraduado de Dermatovenerologia, Serviço de Dermatologia, CHLN/Graduated Consultant \\ of Dermatology, Dermatology Department, CHLN, Lisboa; Professor Auxiliar Convidado de Dermatologia da FML/ \\ Professor of Dermatology and Venereology \\ ${ }^{3}$ Assistente Hospitalar Graduado de Dermatovenerologia, Serviço de Dermatologia, CHLN/Graduated Consultant of \\ Dermatology, Dermatology Department, CHLN, Lisboa; Professor de Dermatologia da FML/Professor of Dermatology \\ and Venereology
}

*Instituto de Higiene e Medicina Tropical, Lisboa, Portugal

\#Unidade de Investigação em Dermatologia, Instituto de Medicina Molecular, Lisboa, Portugal

${ }^{\S}$ Faculdade de Medicina, Universidade de Lisboa, Portugal

RESUMO - Introdução: Nos últimos anos tem-se verificado um ressurgimento da sífilis. A infecção pelo Treponema pallidum encontra-se sobretudo associada ao uso inconsistente do preservativo e ao elevado número de parceiros sexuais nos meses que precedem o diagnóstico. Na sequência do aumento do número de casos diagnosticados, torna-se premente uma maior sensibilização das características clínico-patológicas da doença. Este artigo descreve e correlaciona as características clínicas e histopatológicas de sífilis secundária em 7 doentes observados no Serviço de Dermatologia do Hospital Santa Maria, em Lisboa, Portugal. Material e Métodos: Foram estudadas nove biópsias de lesões mucocutâneas de sete doentes com sífilis secundária, observados entre 2009 e 2013, tendo sido correlacionados os achados histopatológicos com os achados clínicos. Resultados: O presente estudo revelou um largo espectro de alterações histopatológicas que variam desde um infiltrado inflamatório com localização à derme superficial até uma extensão perivascular na derme profunda. Apesar de se verificar alguma correlação entre os diversos padrões de inflamação e o tipo de lesões cutâneas, as lesões maculares associaram-se com um infiltrado inflamatório superficial enquanto as lesões papulares, maculopapulares e nodulares se associaram a um processo inflamatório profundo. O tipo de célula predominante no infiltrado foi o plasmócito. Os neutrófilos foram observados apenas num caso de condylomata lata. Conclusões: As características histopatológicas de sífilis secundária parecem ser tão variadas como as características clínicas. É da responsabilidade dos profissionais que lidam com estes doentes estarem particularmente atentos à grande variedade semiológica desta patologia, lembrarem-se de o colocar como hipótese diagnóstica clínica e estarem conscientes da necessidade de estabelecer uma estreita interacção com os dermatopatologistas. A colaboração entre patologistas e clínicos permite uma correlação da clínica, serologias e achados histopatológicos de forma a estabelecer mais plausivelmente o diagnóstico de sífilis.

PALAVRAS-CHAVE - Diagnóstico diferencial; Histopatologia; Imunohistoquímica; Sífilis; Treponema pallidum.

\section{SECONDARY SYPHILIS - CLINICOPATHOLOGICAL CORRELATION}

ABSTRACT - Introduction: In recent years there has been a resurgence of syphilis. Infection by Treponema pallidum is mainly associated with inconsistent condom use and high number of sexual partners in the months preceding the diagnosis. Following the increase number of diagnosed cases, it is important to have a greater awareness of the clinical and pathological features of the disease. This article describes and correlates the clinical and histopathological features of secondary syphilis in 7 patients seen at the Department of Dermatology, Hospital Santa Maria, Lisbon, Portugal. Material and Methods: Nine biopsies of mucocutaneous lesions from seven patients with secondary syphilis, observed between 2009 and 2013. The histopathologic and clinical findings were correlated and studied. Results: This study revealed a broad spectrum of histopathological changes ranging from an inflammatory infiltrate of the superficial dermis with location to an extent perivascular in the deep dermis. Although there is some correlation between different patterns of inflammation and type of skin lesions, the macular lesions were associated with a superficial inflammatory infiltrate as papular, maculopapular, and nodular lesions were associated with a profound inflammatory process. The predominant infiltrate was 
plasmacytic. Neutrophils were observed only in the case of condylomata lata. Conclusions: The histopathological features of secondary syphilis appear to be as varied as the clinical ones. It is the responsibility of the professionals who deal with these patients being particularly alert to the wide range of manifestations in this disease, remember this clinical diagnosis and be aware of the need for close interaction with dermatopathologists. The collaboration between pathologists and clinicians allows a correct correlation between clinical, serology and histopathological findings in order to establish a more plausibly diagnosis of syphilis.

KEY-WORDS - Skin, pathology; Skin diseases; Syphilis; Syphilis, cutaneous; Syphilis serodiagnosis.

\author{
Conflitos de interesse: Os autores declaram não possuir conflitos de interesse. \\ No conflicts of interest. \\ Suporte financeiro: $O$ presente trabalho não foi suportado por nenhum subsídio ou bolsa. \\ No sponsorship or scholarship granted. \\ Direito à privacidade e consentimento escrito / Privacy policy and informed consent: Os autores declaram \\ que pediram consentimento ao doente para usar as imagens no artigo. The authors declare that the patient gave \\ written informed consent for the use of its photos in this article.
}

Recebido/Received - Janeiro/January 2014; Aceite/Accepted - Fevereiro/February 2014

Por decisão dos autores, este artigo não foi redigido de acordo com os termos do novo Acordo Ortográfico.

\author{
Correspondência: \\ Dr. Luís Uva \\ Clínica Universitária de Dermatologia de Lisboa \\ Hospital de Santa Maria \\ Av. Prof. Egas Moniz \\ 1649-028 Lisboa, Portugal \\ Tel: +351217805196 \\ Fax: +351217954447
}

\section{INTRODUÇÃO}

A Sífilis é uma doença generalizada e multissistémica causada pelo Treponema pallidum. A sífilis segue clinicamente uma sequência, verificando-se inicialmente o aparecimento de uma lesão primária no local da inoculação, seguida de lesões secundárias, que envolvem toda a superfície da pele, e posteriormente surge a sífilis latente e, eventualmente, a terciária, que ocorre depois de um período de meses a anos ${ }^{1,2}$.

O polimorfismo clínico característico da sífilis justifica que se denomine esta entidade clínica como sendo a "grande imitadora" e que seja necessário o seu diagnóstico diferencial com inúmeras patologias inflamatórias, oncológicas ou mesmo infecciosas provocadas por outros agentes etiológicos ${ }^{3-5}$. É, portanto, desejável que dermatologistas e patologistas estejam familiarizados com a ampla gama de manifestações clínicas e histológicas da doença.
Classicamente, o diagnóstico de sífilis é baseado na análise dos dados clínicos, estudos serológicos e de detecção directa do organismo por microscopia de campo escuro e técnicas de impregnação com prata. $O$ diagnóstico definitivo é conferido apenas pela detecção do organismo nos tecidos infectados ${ }^{6}$.

A serologia constitui o diagnóstico indireto mais frequentemente utilizado, resultando de uma combinação de testes não-treponémicos (VDRL e RPR) e testes treponémicos (FTA-ABS e TPHA). A sua utilização tem-se mostrado útil para o diagnóstico e monitorização de doentes após o início do tratamento, no entanto os testes não-treponémicos estão associados a alguns resultados falsos negativos, devido ao excesso de antigénio (fenómeno prozona). Relativamente aos testes treponémicos, estes apresentam elevada especificidade e sensibilidade em casos de sífilis secundária, verificando-se uma diminuição de ambas nas fases iniciais de infecção, na sífilis congénita e terciária, neurossífilis e na co-infecção com 
$\mathrm{VIH}, \mathrm{VHC}$ e quando a sífilis se associa a outros estados de imunossupressão ${ }^{6}$.

Para a detecção directa de T. pallidum, o microscópio de campo escuro é sensível, mas não específico, e requer a presença de profissionais experientes. As técnicas de impregnação com prata apresentam baixa sensibilidade e baixa especificidade, verificando-se a presença de numerosos artefactos de campo'.

A biópsia com marcação imuno-histoquímica (IHQ) utilizando anticorpos anti-Treponema (AcAT) tem-se revelado igualmente importante no diagnóstico de sífilis permitindo distinguir lesões de sífilis de outras lesões não relacionadas que podem ser vistas em doentes com um verdadeiro positivo ou um falso positivo na serologia para T. pallidum. Além disso, é uma técnica relativamente rápida, com resultados disponíveis dentro de $48 \mathrm{~h}$ e não apresenta um custo elevado 6 . Por isto, cada vez mais, a deteção de Treponema pallidum usando técnicas de PCR tornou-se o "gold standard".

Recentemente, o aumento da incidência de $\mathrm{VIH}$ teve um grande impacto no diagnóstico e tratamento da sífilis. A associação cada vez mais frequente sífilis-VIH aumenta a insegurança na avaliação dos resultados dos testes serológicos considerando-se, desta forma, o exame histopatológico como uma possível ferramenta diagnóstica complementar de relevo².

\section{MATERIAL E MÉTODOS}

Sete pacientes com diagnóstico de sífilis secundária foram observados e estudados no Serviço de Dermatologia e Venereologia do Hospital Santa Maria, Lisboa, entre Abril de 2009 e Junho de 2013 (Tabela 1).

Tabela 1 - Características clínicas e serológicas dos 7 casos clínicos de sífilis secundária.

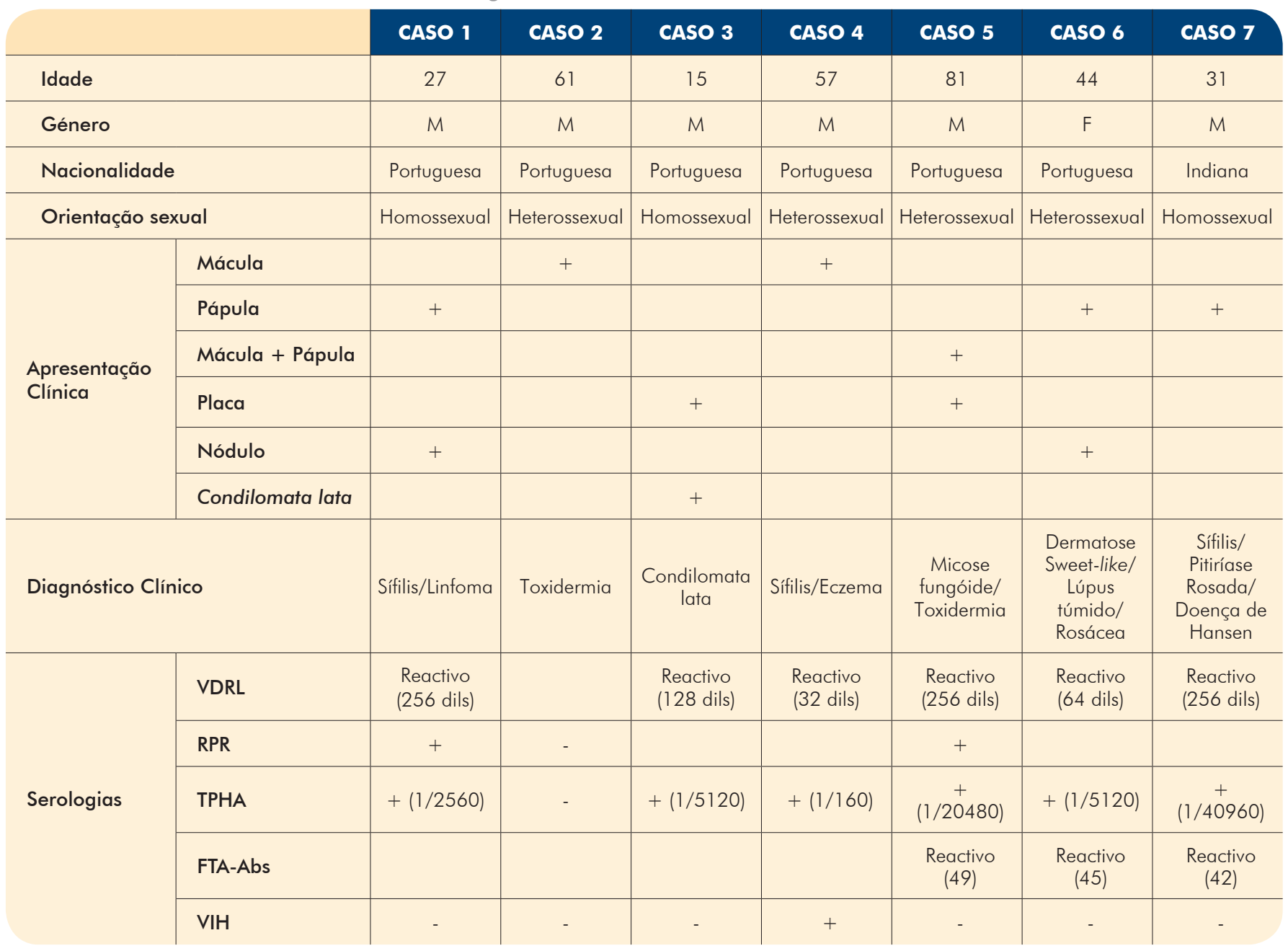




\section{GEIDST}

O diagnóstico de sífilis secundária foi estabelecido pela presença de uma erupção cutânea sugestiva de sífilis, aspectos histopatológicos na biopsia cutânea, positividade dos testes serológicos, desenvolvimento da reacção de Jarisch-Herxheimer e resposta terapêutica ao tratamento com penicilina. Para diagnóstico de infecção por $\mathrm{VIH}$ foi pesquisada, em soro fresco, a presença de anticorpos pelo teste imunoenzimático ELISA (Ensaio de Imunoabsorção Ligado a Enzima); uma amostra positiva foi confirmada pelo método de Western Blot.

Os dados clínicos, incluindo idade e género do doente, bem como as características clínicas das lesões cutâneas foram registados. Nove biopsias de várias lesões mucocutâneas foram colhidas e os tecidos fixados em formol a $10 \%$ de solução salina. Foram efectuados cortes em parafina com 4-6 $4 \mu$ de espessura, os quais foram corados com hematoxilina-eosina para exame microscópico pelos métodos convencionais. No caso clínico sete, foram efectuadas técnicas de coloração com Ácido Periódico de Schiff (PAS) e Ziehl-Neelsen para detecção de fungos / bacilos álcool-ácido resistentes, sendo ambas negativas para microrganismos. Foi utilizado o método de Warthin-Starry $(\mathrm{pH} 4,0)$ modificado para detecção de espiroquetas na biopsia correspondente ao primeiro caso clínico. No caso clínico seis, foram executadas secções adicionais de parafina para estudo imuno-histoquímico pela técnica de avidina-biotina- peroxidase e para amplificação do ADN de Treponema pallidum pela técnica de PCR (Reacção de Polimerização em Cadeia).

\section{RESULTADOS}

Dos pacientes incluídos no estudo, a razão homens: mulheres foi de 6:1. As idades variaram entre 15 e 81 anos, com uma idade média de 42 anos e uma mediana de 37 anos. Seis dos sete doentes eram de nacionalidade portuguesa e quatro relataram orientação heterossexual. O teste de ELISA para detecção de anticorpos do $\mathrm{VIH}$ foi positivo em apenas um doente do sexo masculino. Foi efectuada confirmação da positividade do teste pela técnica de Western Blot (anti-VIH1 +).

Sem história de acidente primário, as lesões cutâneas foram a forma de apresentação característica em todos os pacientes (Fig. 1). A natureza das lesões cutâneas biopsadas foi máculo-papular em 6 doentes, constituída por placas/nódulos em 4 e papular húmida (condylomata lata) em 1 (Tabela 1).

As características histopatológicas variaram de acordo com a morfologia clínica da erupção e com o tempo
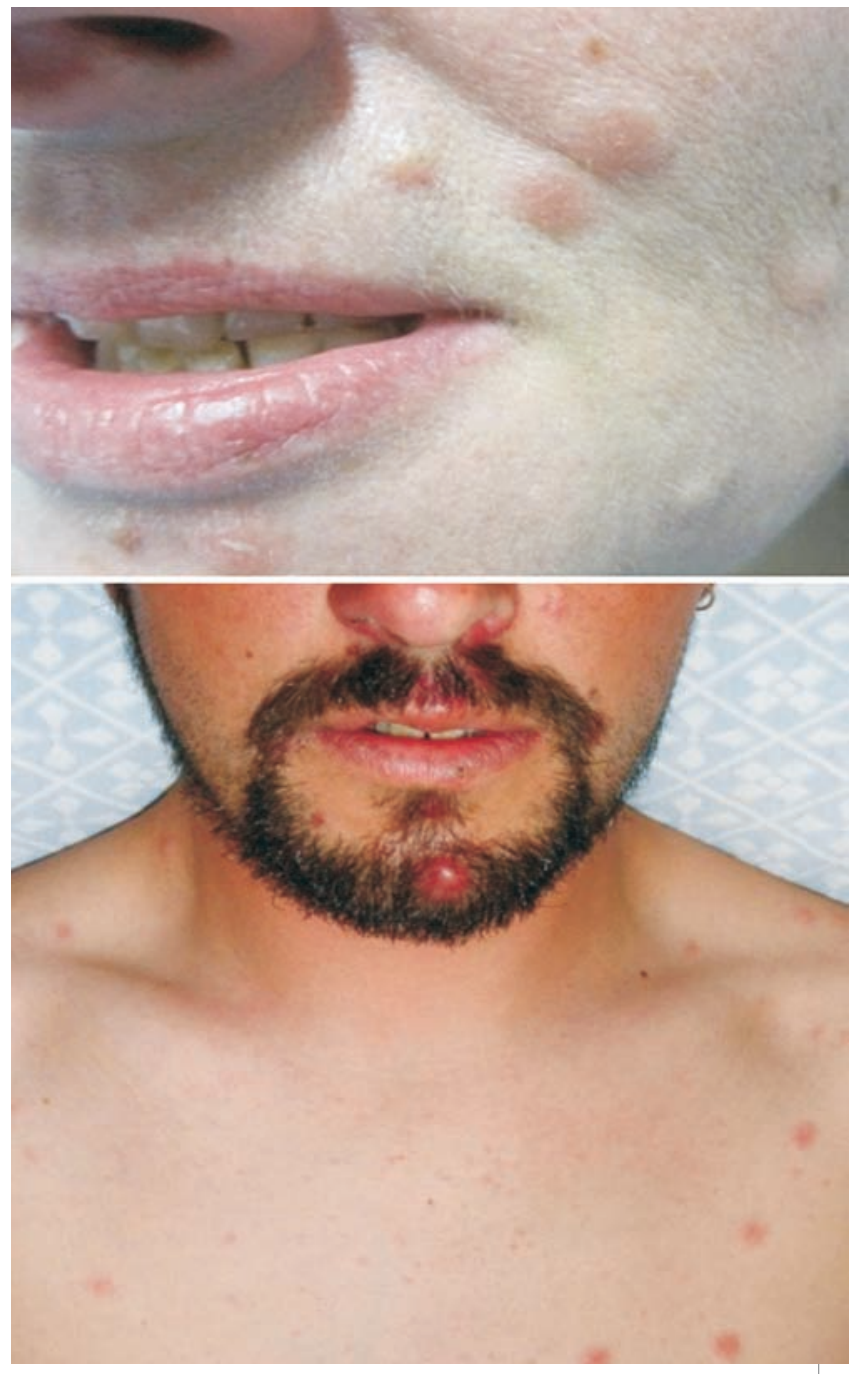

Fig 1 - Sífilis secundária. Aspectos clínicos. (a) Pápulas e nódulos eritematosos na face; (b) Pápulas eritematosas, túmidas, disseminadas, nódulo mentoniano.

decorrido desde o início da infecção. Na Tabela 2, apresentam-se os resultados considerados mais marcantes.

Os padrões histológicos foram classificados em geral como: (1) liquenóide, (2) superficial, (3) perianexial, (4) perivascular superficial e (5) perivascular superficial e profundo.

As biopsias correspondentes aos pacientes com lesões sifilíticas maculares (casos clínicos 2 e 4), revelaram a presença de um infiltrado linfoplasmocitário perivascular na derme superficial (Fig. 2b). No caso clínico 4 observou-se um padrão liquenóide. Nestas lesões, a epiderme foi envolvida pelo processo inflamatório, observando-se paraqueratose focal, acantose e ortoqueratose (Fig. 2a). 


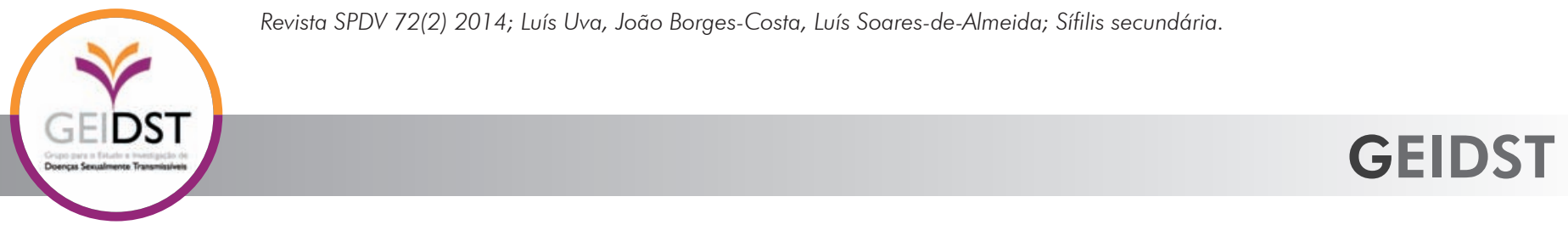

Tabela 2 - Características histológicas dos 7 casos clínicos de sífilis secundária.

\begin{tabular}{|c|c|c|c|c|c|c|c|c|c|}
\hline & & & CASO 1 & CASO 2 & CASO 3 & CASO 4 & CASO 5 & CASO 6 & CASO 7 \\
\hline \multirow{14}{*}{ 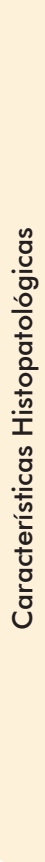 } & \multirow{4}{*}{$\begin{array}{l}\text { Alterações } \\
\text { Epidérmicas }\end{array}$} & Acantose & & & + & + & & + & + \\
\hline & & Paraqueratose & & + & + & & & & + \\
\hline & & Ortoqueratose & + & & & + & + & + & \\
\hline & & Atrofia & & & & & + & & \\
\hline & \multirow{5}{*}{$\begin{array}{l}\text { Padrão } \\
\text { Histopatológico } \\
\text { de Inflamação na } \\
\text { derme }\end{array}$} & Liquenóide & & & + & + & & & \\
\hline & & $\begin{array}{l}\text { Superficial } \\
\text { intersticial }\end{array}$ & & & & + & & + & \\
\hline & & Perianexial & & & & & + & & + \\
\hline & & $\begin{array}{l}\text { Perivascular } \\
\text { (superficial) }\end{array}$ & & + & & + & & & \\
\hline & & $\begin{array}{l}\text { Perivascular } \\
\text { (superficial e } \\
\text { profundo) }\end{array}$ & + & & & & + & + & + \\
\hline & \multirow{5}{*}{$\begin{array}{l}\text { Células } \\
\text { Inflamatórias }\end{array}$} & Plasmócitos & + & + & ++ & + & ++ & + & + \\
\hline & & Neutrófilos & & & + & & & & \\
\hline & & Linfócitos & + & + & + & + & & ++ & + \\
\hline & & Eosinófilos & & & & & & & \\
\hline & & Histiócitos & ++ & & & & & + & ++ \\
\hline
\end{tabular}

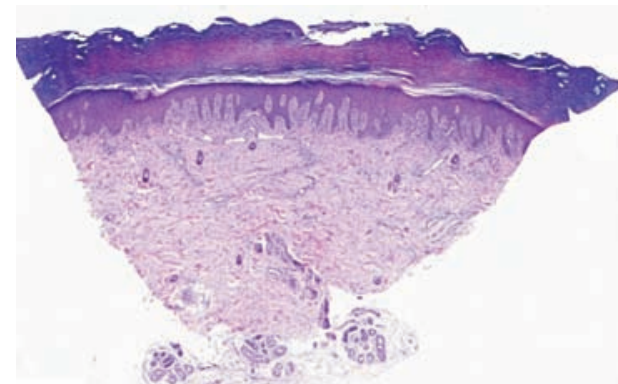

a)

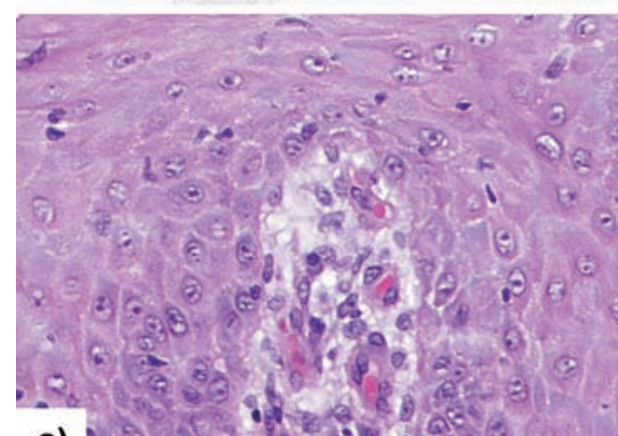

c)

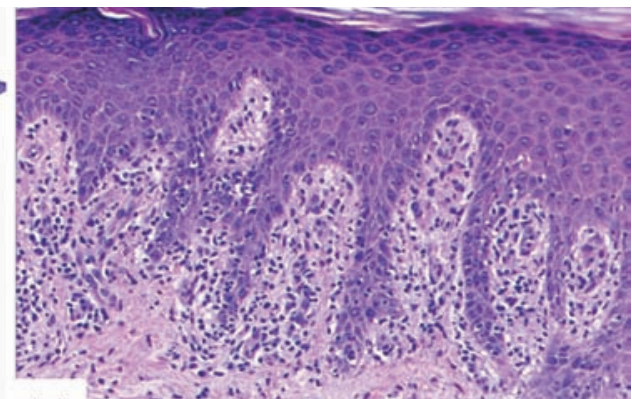

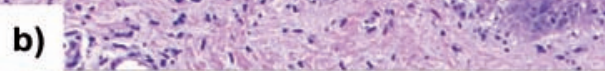

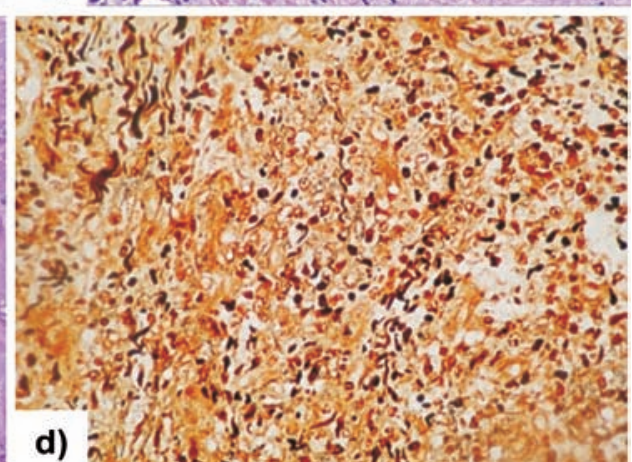

Fig 2 - Sífilis secundária. Aspectos histopatológicos. (a) Hiperquerałose ortoqueratósica sobre acantose irregular da epiderme; (b) Infiltrado linfoplasmocitário em banda na derme superficial e epidermotropismo focal; (c) Plasmócitos na derme; (d) Agregados de T. pallidum na derme papilar pela coloração de Warthin-Starry (impregnação de sais de prata). 


\section{GEIDST}

Nos doentes em que apresentação clínica de sífilis secundária ocorreu sob a forma de pápulas, o infiltrado inflamatório tinha uma disposição perivascular na derme superficial e profunda e era mais denso do que nas lesões maculares. No caso clínico 7 verificou-se um envolvimento perianexial. Em todas as biópsias foram observados plasmócitos (Fig. 2c), linfócitos e histiócitos. As alterações epidérmicas foram similares às encontradas nas máculas. No caso clínico 7 , a erupção cutânea foi apenas papular enquanto nos casos 1 e 6, as pápulas se associaram a lesões nodulares. No caso clínico 6, adicionalmente à dermatose, a doente tinha febre e, laboratorialmente, leucocitose com um quadro clínico sugestivo de Síndrome de Sweet. Foi realizada coloração de Warthin-Starry no caso clínico 1, a qual terá permitido a observação de múltiplas inclusões argentafins correspondentes a agregados de $T$. pallidum (Fig. 2d).

No caso clínico 5, as lesões maculopapulares observadas traduziram-se histopatologicamente na presença de um infiltrado plasmocitário perivascular na derme superficial e profunda circundando os anexos
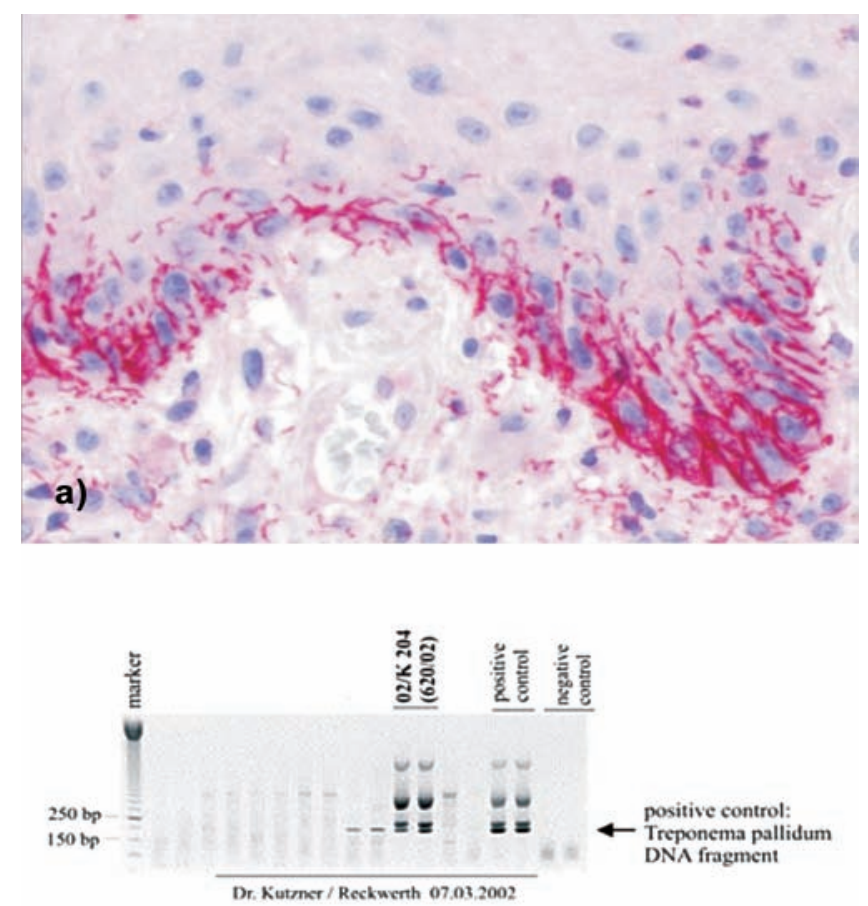

b)

Fig 3 - Sífilis secundária. (a) Imunohisoquímica - Espiroquetas em grande número na epiderme; (B) PCR Confirmada presença de Treponema pallidum. cutâneos. A epiderme revelou algum grau de atrofia, com ortoqueratose.

A forma clínica de apresentação em placas observou-se apenas em 2 doentes. No caso clínico 5 verificou-se uma erupção cutânea disseminada constituída por máculas, pápulas e placas eritemato-violáceas. $\bigcirc$ segundo doente, por sua vez, tinha várias placas eritematosas circulares com discreta descamação periférica, localizadas na região peniana, compatíveis com o diagnóstico de condylomata lata. Microscopicamente, a amostra biopsada revelou acantose regular e hiperplasia psoriasiforme da epiderme com exocitose de neutrófilos, microabcessos intracórneos e um infiltrado linfocitário, perivascular e intersticial, rico em plasmócitos, na derme superficial.

No estudo imuno-histoquímico complementar, realizado na abordagem do caso clínico 6, foram detectadas espiroquetas em grande número na epiderme (Fig. $3 a)$. Foi confirmada a presença de $T$. pallidum pela técnica de PCR (Fig. 3b).

\section{DISCUSSÃO}

Os resultados do estudo histopatológico das biopsias obtidas a partir dos 7 doentes com sífilis secundária estão de acordo com a diversidade das manifestações cutâneas nesta doença.

O polimorfismo das manifestações cutâneas levou a que nestes doentes, para além da sífilis secundária, fossem colocadas outras hipóteses de diagnóstico diferencial, sendo as mais frequentes o linfoma cutâneo e a toxidermia. Estas hipóteses de diagnóstico clínico e a possibilidade de ocorrência do fenómeno prozona, em conjunto com as análises utilizadas no diagnóstico (p.ex. caso clínico 1), conduziram à realização de biopsias cutâneas, neste grupo de doentes.

À semelhança de estudos anteriores demonstrou-se a presença de uma discreta reacção inflamatória cutânea nos pacientes em que a apresentação clínica de sífilis secundária ocorreu sob a forma de uma erupção macular; nas lesões maculopapulares e papulares, as alterações epidérmicas e dérmicas foram mais acentuadas. As lesões de condylomata lata tiveram uma aparência histopatológica distinta observando-se acantose, hiperplasia psoriasiforme, exocitose e um infiltrado denso plasmocitário em torno e entre os vasos sanguíneos da derme.

A presença de plasmócitos em todas as amostras biopsadas reforça o status destas células como a marca da resposta inflamatória na sífilis secundária. As 
entidades patológicas equacionadas no diagnóstico diferencial, nomeadamente eritema multiforme, líquen plano, psoríase e pitiríase liquenóide, raramente contêm um componente plasmocitário e, nestas situações, apesar de não ser patognomónico, mantém o seu valor diagnóstico. Além disso, na sífilis secundária, os eosinófilos, presentes frequentemente em reacções medicamentosas, são raros e o infiltrado inflamatório estende-se superficial e profundamente, enquanto no líquen plano e reacções liquenóides este é sobretudo superficial ${ }^{3,7}$.

A detecção de treponemas pela coloração de Warthin-Starry (impregnação de sais de prata) é pouco representativa, uma vez que, muitos dos componentes de tecido normal, tais como grânulos de melanina e fibras de reticulina são também corados, podendo ser confundidos com treponemas ${ }^{2,4,7}$.

A utilização de um anticorpo monoclonal para Treponema pallidum através da técnica de imunohistoquimica parece ser um método mais sensível (71\%) e específico na detecção de espiroquetas, em comparação com o método de coloração de prata $(41 \%)$. (J. Cutan Pathol. 2004 Oct;31(9):595-9. Secondary syphilis: a histologic and immunohistochemical evaluation. Hoang MP, High WA, Molberg KH). A imunohistoquimica constitui assim um método melhorado de detecção de espiroquetas em cortes de tecido assumindo um papel importante no contexto do aumento da incidência de sífilis secundária seronegativa em pacientes com infecção pelo $\mathrm{VIH}$, importante para se evitar a ocorrência precoce de sequelas nestes indivíduos ${ }^{4}$.

Nas fases assintomáticas da doença, o diagnóstico com base em técnicas de PCR tem sido descrito com sensibilidade e especificidade pouco elevadas.

No diagnóstico de sífilis, o estudo histopatológico, é realizado em simultâneo com testes serológicos, destacando-se a importância dos testes treponémicos, como - TPHA, cuja realização é sugerida pela International Union against Sexually Transmitted Infections (IUSTI). Os testes não treponémicos (VDRL e RPR), apesar de realizados com maior frequência, estão associados a um maior número de resultados falsos negativos (fenómeno prozona), sendo estes particularmente mais frequentes na coinfecção VIH e sífilis.

Atendendo à reduzida dimensão da amostra utilizada neste estudo, não podemos considerar a existência de uma correlação significativa entre as características das lesões cutâneas, títulos serológicos, densidade e distribuição do infiltrado inflamatório na derme e número de plasmócitos. Apesar da heterogeneidade relativa dos achados histológicos poderem reduzir o valor diagnóstico da biopsia cutânea, no presente momento, a correlação clínica-patológica, juntamente com estudos serológicos continuam a ser essenciais para estabelecer o diagnóstico final de sífilis secundária. Desta forma, é necessário que se estabeleça uma relação estreita com - laboratório de dermatopatologia, sempre que exista um elevado grau de suspeição clínica de sífilis, mesmo que a abordagem analítica ou histológica não forneça resultados sugestivos desta doença ${ }^{3,4,7}$.

\section{BIBLIOGRAFIA}

1. Macaron NC, Cohen C, Chen SC, Arbiser JL. Cutaneous lesions of secondary syphilis are highly angiogenic. Journal of the American Academy of Dermatology. 2003;48(6):878-81.

2. Pandhi RK, Singh N, Ramam M. Secondary syphilis: a clinicopathologic study. Int J Dermatol. 1995;34(4):240-3.

3. Alessi E, Innocenti M, Ragusa G. Secondary syphilis. Clinical morphology and histopathology. Am J Dermatopathol. 1983;5(1):11-7.

4. Hoang MP, High WA, Molberg KH. Secondary syphilis: a histologic and immunohistochemical evaluation. J Cutan Pathol. 2004;31(9):595-9.

5. Vanconcelos P, Fraga A, Costa JB, Soares de Almeida L, Marques MS. Fenómeno prozona em sífilis secundária. A importância da comunicação entre o clínico e o laboratório. Trab Soc Port Dermatol Venereol. 2012;70(1):113.

6. Hernández C, Fúnez R, Repiso B, Frieyro M. Utilidad de la inmunohistoquímica con anticuerpos antitreponema en el diagnóstico de la sífilis. Actas Dermosifiliogr. 2013;104:926-8.

7. McMillan A, McQueen A, McLaren C. A histopathological study of secondary syphilis. J Eur Acad Dermatol Venereol. 1996;7(3):235-9. 